\title{
Undergraduate Research in a Materials Independent Study at a Small Col- lege: From Building Modern Fabrication Equipment to Experimental Testing
}

\section{Dr. Tristan M. Ericson, York College of Pennsylvania}

Dr. Tristan Ericson joined the faculty at York College of Pennsylvania as an Assistant Professor in 2013. Prior to this appointment, he was a Visiting Professor at Bucknell University. His teaching interests include solid mechanics, vibrations, materials science, and MATLAB. He also advises the YC Racing FormulaSAE team. His technical research interests include vibrations of planetary gear systems, strengthening 3D printed materials, and making things go faster. He enjoys activities that promote STEM fields in local high schools. He received his PhD from Ohio State University in 2012.

\section{Dr. Stephen N Kuchnicki, York College of Pennsylvania}

Dr. Stephen Kuchnicki has been an Assistant Professor of Mechanical Engineering at York College of Pennsylvania since January 2008. Previously, he was a postdoctoral research associate at Rutgers University, specializing in computational modeling of dynamic deformations in solids. His areas of technical expertise include solid mechanics, crystal plasticity, vibration, and fluid-structure interaction. He received his Ph.D. from Rutgers University in 2001. 


\title{
Undergraduate Research in a Materials Independent Study at a Small College: From Building Modern Fabrication Equipment to Experimental Testing
}

\begin{abstract}
The number of advanced engineering electives at smaller programs is often limited. When a group of York College of Pennsylvania mechanical engineering juniors took our curriculumstandard Materials Science course in 2016, there was sufficient interest among several students to consider offering an advanced topics course. Rather than create an advanced course for limited enrollment, faculty and students developed an independent study focused on designing/building fabrication equipment and testing the material properties of specimens produced by these machines. Four students designed and built a 3D printer and a thermoforming machine. These machines were used to create tensile test specimens to analyze (1) material degradation due to aqueous environment exposure, (2) effect of raster and print orientation, (3) strengthening by epoxy impregnation, and (4) strength as a function of orientation in thermoformed materials. The independent study spanned two semesters for six total credits. The first semester focused on designing and building the machines, and the second semester was dedicated to fabricating and testing material specimens. Experimental results reveal several interesting conclusions among the four focus areas. The overall experience of pursuing the independent study over developing an advanced course was quite positive. It was important to have interested and dedicated students on this project, which was ultimately fairly time-consuming. It was also essential to extend the work across two semesters to successfully complete all phases of the project: design, build, create specimens, test, and analyze data.
\end{abstract}

\section{Introduction}

Undergraduate research is a great mechanism for students to apply their basic skills, develop experimental methods, and to address challenging and difficult problems. Kuh [1] identified this as one "high-impact" educational experience. Research forces students to wrestle with a problem in much more detail - and for a much longer amount of time - than the majority of the undergraduate curriculum. It is suitable preparation for academia and industry alike [2], [3], [4], and it provides a unique experience unlike other coursework. Despite challenges inherent at small institutions (limited funding, less student experience/ability, a general focus on teaching), undergraduate research is growing in smaller schools [5]. Over the past two decades there has been increased research into the phenomenon, and challenges, of undergraduate research in traditional four-year institutions [6], [7], [8], [9]. Limited undergraduate student time and ability is a key factor, but small institutions also lack some important support systems. Brey et al. [10] note that graduate student mentors are extremely useful, and Fairley et al. [11] explain how student peer mentors help mitigate the growing pains of entering the research environment for young students. Unfortunately, graduate student peers are resources that many teaching-focused colleges and universities like our institution, York College of PA, do not have. In this case, strong mentorship from - and a good relationship with - faculty advisors becomes increasingly important [12], [13], [14]. Despite challenges faced by small institutions, Lilja [15] notes that undergraduate students have a lot of potential to do research work. York College of PA offers 
only bachelor's degrees in engineering and focuses on teaching courses with smaller class sizes. We desire research activity, but we also wrestle with these limitations discussed above.

York College of PA often uses senior Capstone Design projects as a recruitment tool, but other institutions [16], [17] highlight undergraduate research to draw good students. We would like to increase our undergraduate research activity to diversify faculty activity and provide students with valuable research experiences that may indicate that graduate school is right for them. Egan et al. [18] explains that participation in undergraduate research encourages pursuit of more advanced degrees. Even if students do not move into graduate/professional programs, undergraduate research teaches students critical thinking skills necessary for solving open-ended problems [12], [19]. If done well, there are clearly many advantages of undergraduate research. Independent studies at York College of PA are one of the best mechanisms to offer our students this opportunity.

\section{Relevant Curriculum Background}

Materials Science lecture and lab are taught in the summer after the third year (students' $6^{\text {th }}$ of 8 academic semesters) at York College of PA. The program's three required co-ops present some non-traditional schedule shifts in the last three academic semesters.

There are prime opportunities for independent study work in each of the two senior semesters (first spring, then summer). Independent studies can replace either or both required engineering elective courses. The senior spring is one of the more intense semesters in the program, with Capstone Design II, so students pursuing an independent study would normally do so in the senior summer just before graduation, which is one of the lightest academic semesters.

Table 1: York College of PA Mechanical Engineering course sequence.

\begin{tabular}{|l|c|c|c|}
\cline { 2 - 4 } \multicolumn{1}{c|}{} & Fall & Spring & Summer \\
\hline $\mathbf{1}^{\text {st }}$ year & $\begin{array}{c}1^{\text {st }} \text { academic term } \\
\text { (freshman) }\end{array}$ & $\begin{array}{c}2^{\text {nd }} \text { academic term } \\
\text { (freshman) }\end{array}$ & no academic responsibilities \\
\hline $\mathbf{2}^{\text {nd }}$ year & $\begin{array}{c}3^{\text {rd }} \text { academic term } \\
\text { (sophomore) }\end{array}$ & $\begin{array}{c}4^{\text {th }} \text { academic term } \\
\text { (sophomore) }\end{array}$ & Co-op 1 \\
\hline $\mathbf{4}^{\text {th }}$ year & $\begin{array}{c}5^{\text {th }} \text { academic term } \\
\text { (junior) }\end{array}$ & Co-op 2 & $\begin{array}{c}6^{\text {th }} \text { academic term (junior) } \\
\text { Materials Science lecture and lab }\end{array}$ \\
\hline
\end{tabular}

As a teaching-focused institution without engineering graduate programs, faculty at York College of PA often use independent study semesters to pursue small research projects. The main difficulties with this are (1) faculty usually only get student help for one semester, and (2) it is usually the senior summer which is only 12 weeks and during the students' last semester. Student interest in academics is often lighter due to the combination of this summer term being the last semester and the recent completion of an often intense Capstone Design project. Also, students are gone completely as soon as the semester is over. 


\section{Project Inception}

When the junior cohort of students took Materials Science in summer 2016, there was interest in an advanced materials-based elective course in the senior year. As a small school, we are less capable of offering a wide variety of electives in the senior year. They are usually determined by faculty interest/expertise or adjunct industrial background. Students only have two or three elective options to choose from in each senior semester.

York College of PA has a "hands-on" philosophy applied to a curriculum full of labs, projects, co-ops, and group work. Lilja [15] explains that hands-on experiences foster "a deep understanding and appreciation for a subject and its traditions." This approach, along with the burden of designing a new course in order to offer an advanced materials elective, led to consideration of a multi-student, multi-professor, (possibly multi-semester, which has benefits discussed by Kaul et al. [12]) research-based independent study.

\subsection{Deciding on an Elective Course vs. an Independent Study}

The advantages of pursuing advanced materials as an elective were:

- More organized

- More predictable and more control over the overall result

- Broader coverage of advanced material concepts

- Potentially wider student audience (not all are interested in an independent project)

The advantages of pursuing an independent study with the interested students were:

- More faculty involved with different expertise (especially valuable at an institution with fewer faculty and less specialization)

- The fall semester after the Materials Science course permitted planning to begin the project in the spring and give the project more time with a two-semester option

- Less time required for course design

- Increase our department's research experiences

There were four students who expressed the strongest desire to learn more about materials after the junior course. Faculty thought that this was a good number for an independent study project; Friend and Beneat [5] note that undergraduate research teams should be reasonably small. Additionally, all students involved agreed that the independent study topics aligned with their interests; Kaul et al. [12] explain that this type of engagement is paramount. In the end, the combination of (1) participation of multiple faculty members to draw from individual strengths, (2) lack of time to develop a new course, and (3) the potential of mentoring a student research project drove us toward the independent study option.

\section{Independent Study Overview}

Three faculty members and the four involved students contributed to the project scope and plan. Professors provided a detailed list of possible research topics. Students narrowed the list, and finally, all worked to construct a plan for a first semester of independent study work (3 credits) with the possibility to continue the work into the second senior (summer) semester (potentially 3 more credits). It was clear in the planning process that students desired design and construction as an important aspect of the proposed scope of work. 


\subsection{Scope of Work and Research Plan}

The original list of proposed research topics generated by the faculty considered what was already known about student interest, faculty interest, laboratory capabilities, and time constraints. That list was:

1. Mechanical testing of a variety of 3D printed materials, including common materials infused with strengthening agents. Candidate materials included:

- High strength PETT t-glass

- ABS carbon fiber $5 \%$

- Multi-walled carbon nanotubes

- Industrial high strength nylon

- Nylon co-polymer

- Polycarbonate

- Graphite-infused ABS

2. Mechanical testing of common 3D printed materials with different orientations to investigate how strength is affected if material beads are applied in different directions

3. Building a 3D printer (likely a first-semester option expected to lead into a summer study)

4. Mechanical testing of materials (mostly printed polymers) subjected to various environments (e.g. saltwater)

Three students were interested in building a 3D printer and conducting a variety of experiments on the different materials (each student to have defined experimental roles). Another student who had co-op assignments - and has since graduated and gone to work - at a plastic forming company wanted to build a thermoforming machine and conduct material experiments on thermoformed specimens. His co-op experience clearly gave rise to interest in this project.

A plan solidified with first-semester (spring) objectives for the four students to:

1. Design/build a 3D printer and thermoforming machine that could produce specimens for material testing

a. Three students responsible for the 3D printer

b. One student responsible for the thermoforming machine

2. Design an experimentation procedure for $3 \mathrm{D}$ printed and thermoformed materials

3. Produce a variety of specimens that could be tested, primarily in tension

The option remained for a second semester (summer), which all four students ultimately did pursue. The objectives in the second half of the project were to:

1. Fabricate the material specimens for research

2. Conduct experimental testing, each student concentrating on a different focus area:

1) Material degradation due to aqueous environment exposure,

2) Raster and print orientation,

3) Strengthening by epoxy layering/impregnation, and

4) Strength as a function of orientation in thermoformed materials

3. Conduct experiments and analyze data

4. Write an operation manual for the student-constructed fabrication machines

5. Draft one or more conference proceedings papers 


\subsection{Instructor Roles}

Three faculty members formulated the independent study work and advise the project through the first semester. Two faculty members continued into the second semester once the group decided to continue work. Having multiple faculty advisors on the project was useful because each person brought a different skillset, including 3D printing, material testing, and research methods.

\subsection{Team Organization}

Three students worked together to design and build the 3D printer. They worked more independently, though still relied on each other to a fair degree, in the second semester to produce and test specimens. The fourth student worked mostly independently to design and build the thermoforming machine, though he received a lot of help from the 3D printing group and other friends to accomplish his objectives. The three faculty members advised all students equally in the first semester (spring), as did the two faculty continuing on the project for the second semester (summer).

\subsection{Grading}

Course grades were evaluated for each student based the following four areas.

- 25\%: Engineering notebook: A journal of activities evaluated bi-weekly

- 50\%: Milestones: Evaluation at each major milestones (dates subject to change after discussion with faculty)

- 10\%: Professionalism: Working professionally with other students and professors

- 15\%: Final technical report: A summative report (individual in the first semester, in pairs according to research similarities in the second semester)

A simple rubric was used to evaluate the engineering notebook considering quality of entries, presentation of work at weekly meetings, and demonstration of tangible progress. The same grading breakdown was used in both semesters.

\section{Phase 1: Design and Build in the First Semester (spring 2017)}

The primary objectives for the first semester of the independent study were to research, design, build, and prove functionality of both fabrication machines: a 3D printer capable of handling multiple materials and a thermoforming machine. Functionality would be proven by fabricating some of the test specimens for second semester experimentation. At York College of PA, we have been more successful with Capstone Design projects with well-defined deliverables with target dates, which we call "milestones." We believed that we should apply this philosophy to the independent study to keep the project on task and moving. This was also recommended by Friend and Beneat [5]. To that end, we expanded the primary objectives to a comprehensive list of ten detailed objectives. We then summarized the detailed objectives in the following milestone list. Completion of these objectives was the dominant metric for establishing student grades. 
1. Finalize research on 3D printers and thermoforming machines: 2/3/17

2. Present finalized design of machines with all relevant documentation (e.g. drawings, BOM, specs. and capabilities, methods of control): 2/17/17

3. Finalize construction of machines: 3/17/17

4. Successfully print/fabricate test quality sample: $4 / 7 / 17$

5. Complete literature review (approx. 15-20 references): 4/12/17

6. Develop test procedure (for running an experiment on a single specimen) and present test plan for summer research: 4/21/17

7. Successfully test three sample specimens: $4 / 28 / 17$

8. Fabricate $50 \%$ of samples needed for summer research: $5 / 5 / 17$

It understandably became necessary to have some flexibility with project milestone dates, depending on project progress and obstacles encountered, but all milestones were ultimately evaluated. Each student received credit according to the milestones on which he worked. Two students took well to the literature review with little guidance, although research by Beaufait et al. [20] suggests that undergraduates will do better with a reading list to get started.

\subsection{First Semester Work/Results}

The students were successful in their primary objective of the first semester: designing and building the fabrication machines. Of course, getting the machines to work properly took longer than the students expected, but the machines were ultimately functional by semester end (with allowances for some improvement/modification in the beginning of the second semester). We report, to no great surprise, that students have a poor ability to estimate how hard a project is or how long a task would take, similar to conclusions by Kaul et al. [12]. This observation resonates with Luchini-Colbry who noted that early researchers can not identify if a task will be simple or challenging [21]. Professors considered whether we should spend so much time designing and building machines that could be purchased at reasonable cost. Buying machines would let us focus on experimentation and analysis, but we wanted to give the students a strong say in the overall project, and building their own machines is what they wanted to do! Lilja [15] explains that student interest in the research activities is a key component to project success. Laying out the project plan and deliverables was an exercise, for us, in letting the students have autonomy to make decisions themselves while not letting them commit to unrealistic goals.

Figure 1 shows (a) the solid model of the 3D printer design and (b) the final working machine. The students considered several basic printer designs, such as Cartesian, Delta, and Polar. Their decision matrix ultimately steered them toward an H-bot/CoreXY design, a subtype of the Cartesian form. It uses a gantry system in the shape of an "H" to move printer heads in the XY plane and motors that drive threaded rods to raise/lower the gantry in the $\mathrm{Z}$ direction. Figure 2 shows (a) the gantry system prototype and (b) belts used to move the printer heads in the XY plane. Note that spacers are used to position the pulleys in the vertical $\mathrm{Z}$ direction to prevent the belts from contacting when they cross paths.

A single student was responsible for designing and fabricating the thermoforming machine. Although there were four total students, three worked together on the 3D printer and only one was in charge of the thermoforming aspect of the project. This decision was entirely student 
driven, based on interest. We certainly did not prefer this uneven split, but the student on the thermoforming aspect of the project was able to solicit a lot of outside help from the three 3D printing students, other classmates, and some resources at the plastics company where he had been a co-op student. We were, understandably, more flexible with milestone completion dates related to the thermoforming machine. Figure 3 shows (a) the solid model of the thermoforming machine and (b) the final working machine.

By semester end, the machines were capable of producing tensile test specimens. Further improvements would be made early in the second semester, but with a lot of work, the students were able to 3D print and thermoform at the semester change. To meet that goal, the students put a lot of extra time and effort into their work. They were intrinsically motivated and willing to put in extra effort to see the project through.
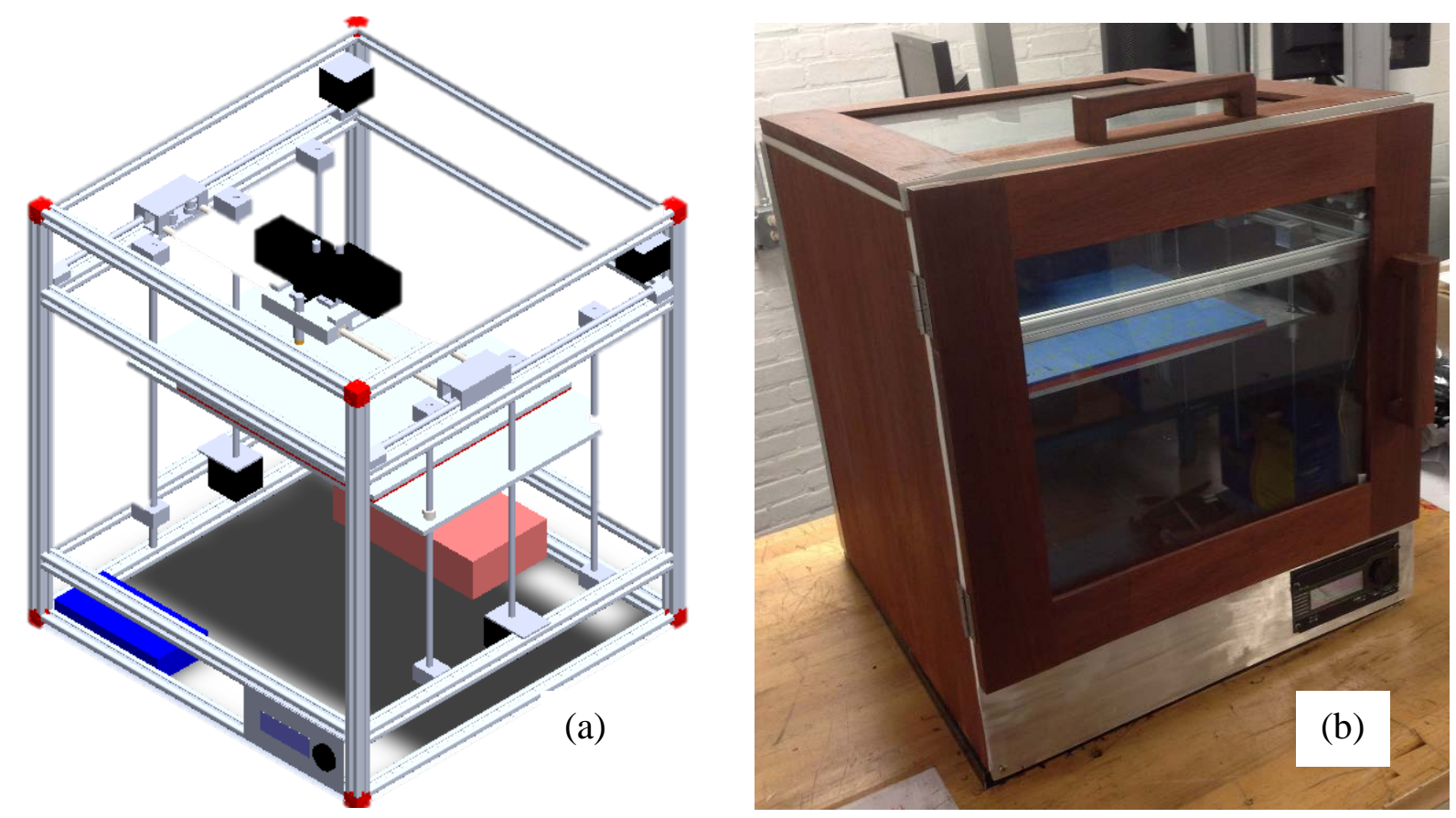

Figure 1: 3D printer designed and fabricated by students (a) solid model, and (b) final machine.

\section{Phase 2: Specimen Fabrication and Material Testing in the Second Semester (summer)}

Second semester work was completed in the students' last academic term, summer of the $4^{\text {th }}$ year. This semester is a few weeks shorter than spring/fall terms ${ }^{1}$. The primary objectives of this semester were to use the machines to produce tensile test specimens, conduct a series of experiments (each student responsible for one focus area), collect/analyze data, and prepare a draft for some form of conference publication. We did not decide beforehand how many papers might come out of the work, but by project end we decided on two.

\footnotetext{
${ }^{1}$ Summer semesters are 12-13 weeks, but fall and spring semesters are 14-15 weeks.
} 

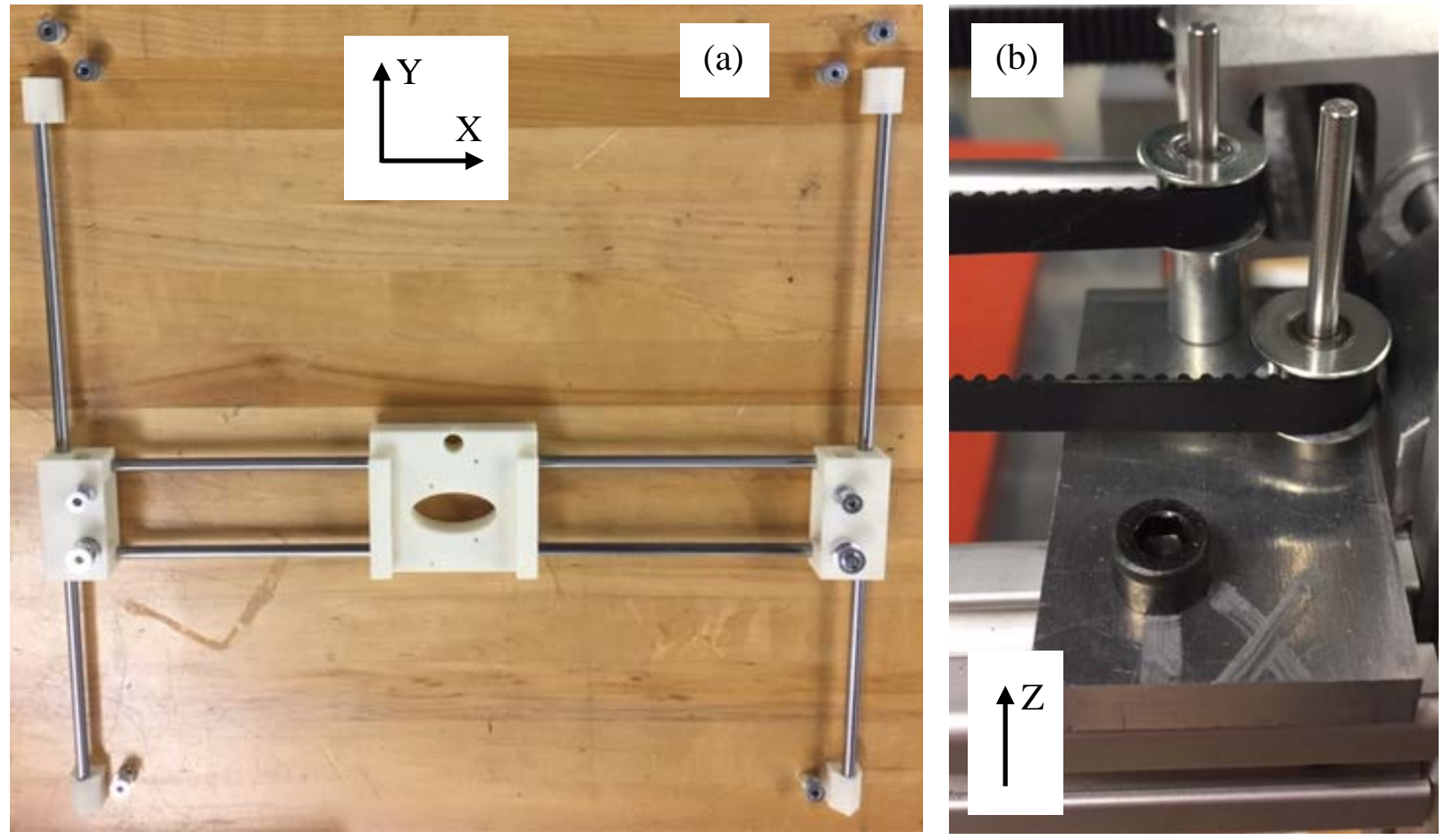

Figure 2: 3D printer (a) gantry system prototype, and (b) pulley brackets, pulleys, and spacers.
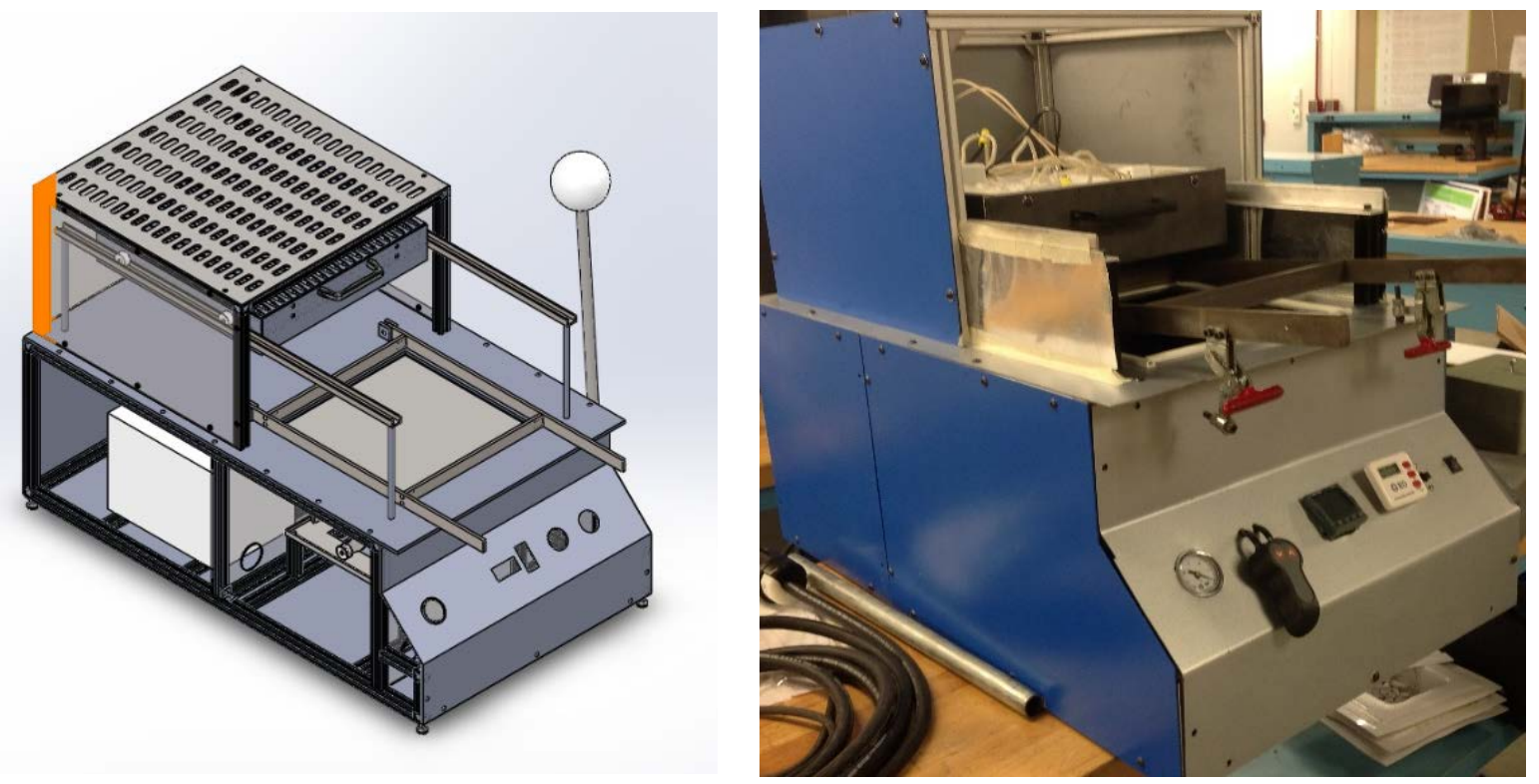

Figure 3: Student designed/built thermoforming machine (a) solid model, and (b) final product. 


\subsection{Second Semester Work/Results}

The 3D printer group of three students did not work as closely together in the second semester because each student had individualized research objectives. All students would use a Tinius Olsen 50ST tensile tester in our materials lab to determine material properties, but the focus of each student was different. The following four focus areas of study (one per student) were chosen and delegated by the students. We will show test specimens and some major findings, but technical results are not the focus of this paper.

Aqueous Environment Exposure: Figure 4 shows the PLA and ABS ASTM D638-02a Type I specimens that were used in aqueous environment exposure experiments. Specimens were tested after exposure to distilled water or saltwater for 24 hours to one month. Short-term exposure to distilled water increased specimen strength, but no change was noted after long-term exposure, compared to a control sample set. Short-term exposure to saltwater decreased strength, but longterm exposure showed an increase in strength over the control.

Raster and Print Orientation: The student responsible for this study tested specimens printed with three different raster orientations in the XY plane (Figure 3a) and one raster orientation in the XZ plane. Figure 5 shows the four different configurations. Results support prior research claiming that more material oriented along the load axis increases strength [22]. The $45^{\circ} /-45^{\circ}$ $\mathrm{XY}$ and concentric XY configurations performed the best overall.

Epoxy Layering/Impregnation: Making a composite from PLA and epoxy is generally regarded to increase strength over the base plastic. This research task looked at a variety of epoxy fill orientations to find optimum combinations of strength/weight and epoxy/weight. Figure 6 shows a control (no epoxy) on the left and five alternative designs suitable for epoxy layering. Experiments show that geometry of PLA/epoxy layering plays a significant role in strength, not just the overall amount of epoxy or the ratio of PLA to epoxy mass.

Thermoformed Material Orientation: The thermoforming machine was used to extrude a trapezoidal ABS form with an aluminum epoxy resin mold. ASTM D36-02a Type IV specimens were cut from various regions of the extruded form: the base and the side walls. Figure 7 shows (a) an extrusion made by the thermoforming machine similar to ones from which specimens were cut (this one was rejected for incomplete vacuum) and (b) material test specimens. Results show a reduction in ultimate stress and ductility of thermoformed ABS plastic for thin specimens, but not with a $50 \%$ increase in thickness. 

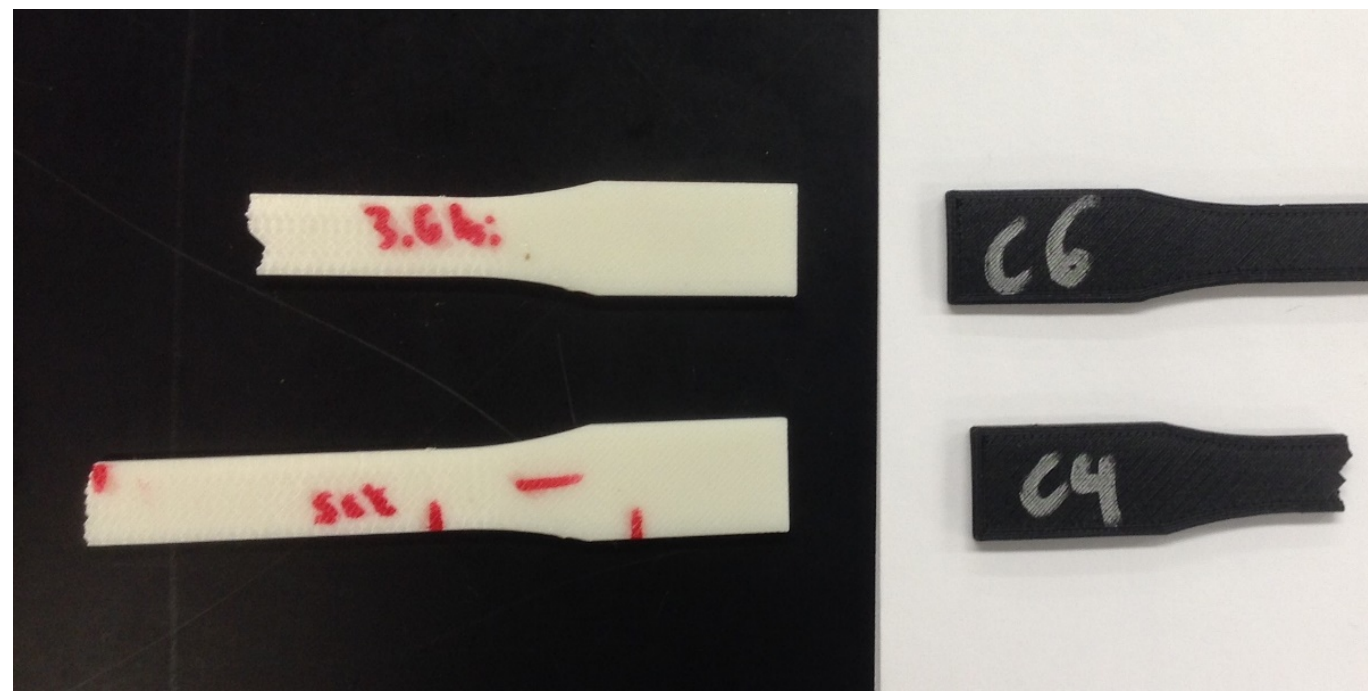

Figure 4: Tensile tested ASTM D638-02a Type I specimens fabricated from (left) ABS and (right) PLA for aqueous environment exposure experiments.

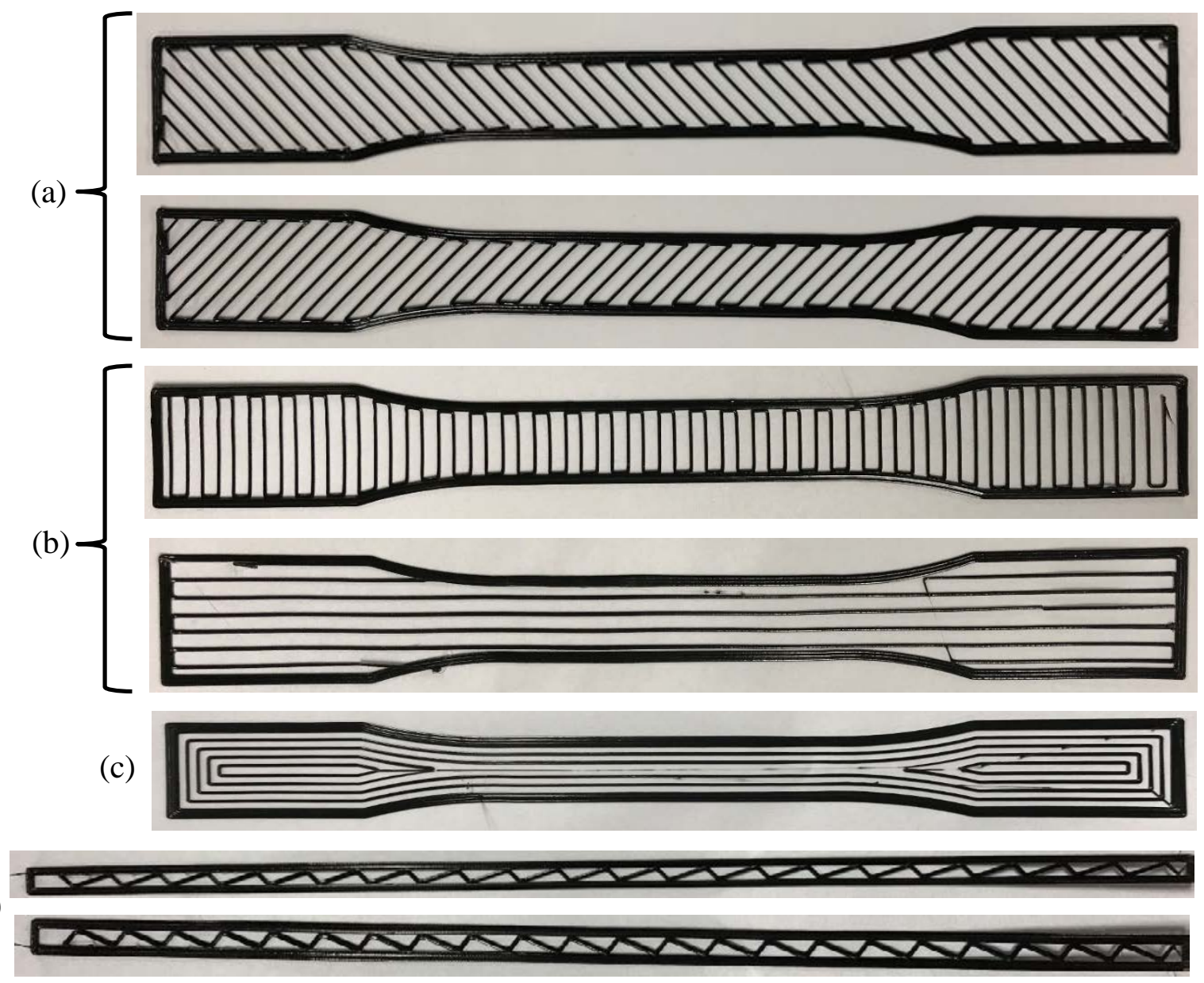

Figure 5: Raster and print orientations tested in (a) $45^{\circ} /-45^{\circ} \mathrm{XY}$ configuration, (b) $0^{\circ} / 90^{\circ} \mathrm{XY}$ configuration, (c) concentric XY configuration, and (d) $45^{\circ} /-45^{\circ} \mathrm{XY}$ configuration. 

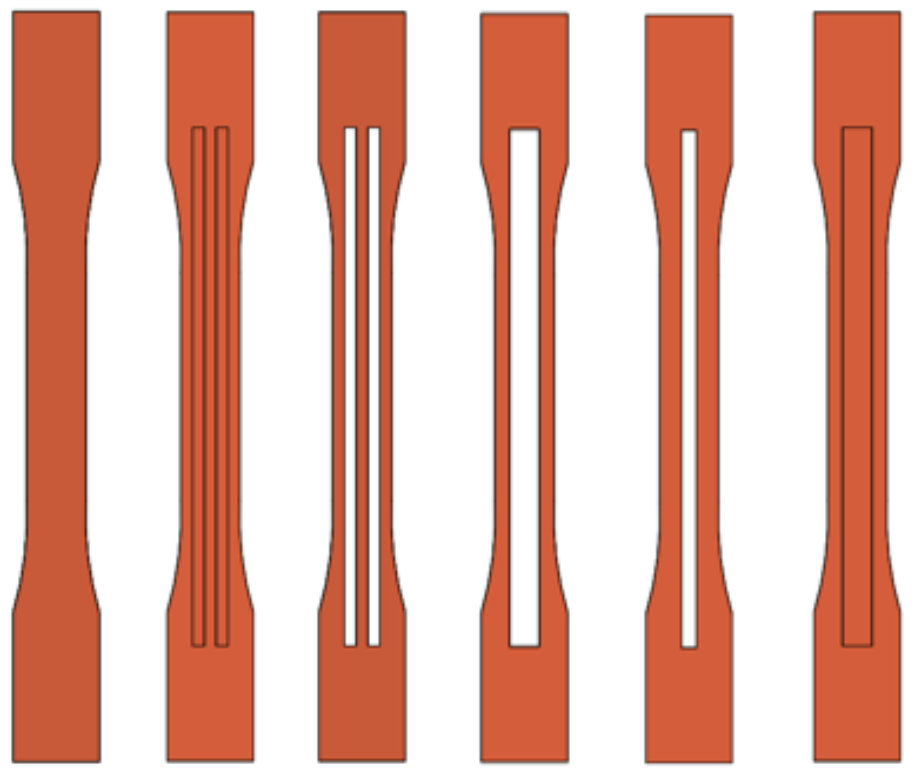

Figure 6: ASTM D638-02a Type I specimens with channels (thru and half thickness) cut for epoxy fill.
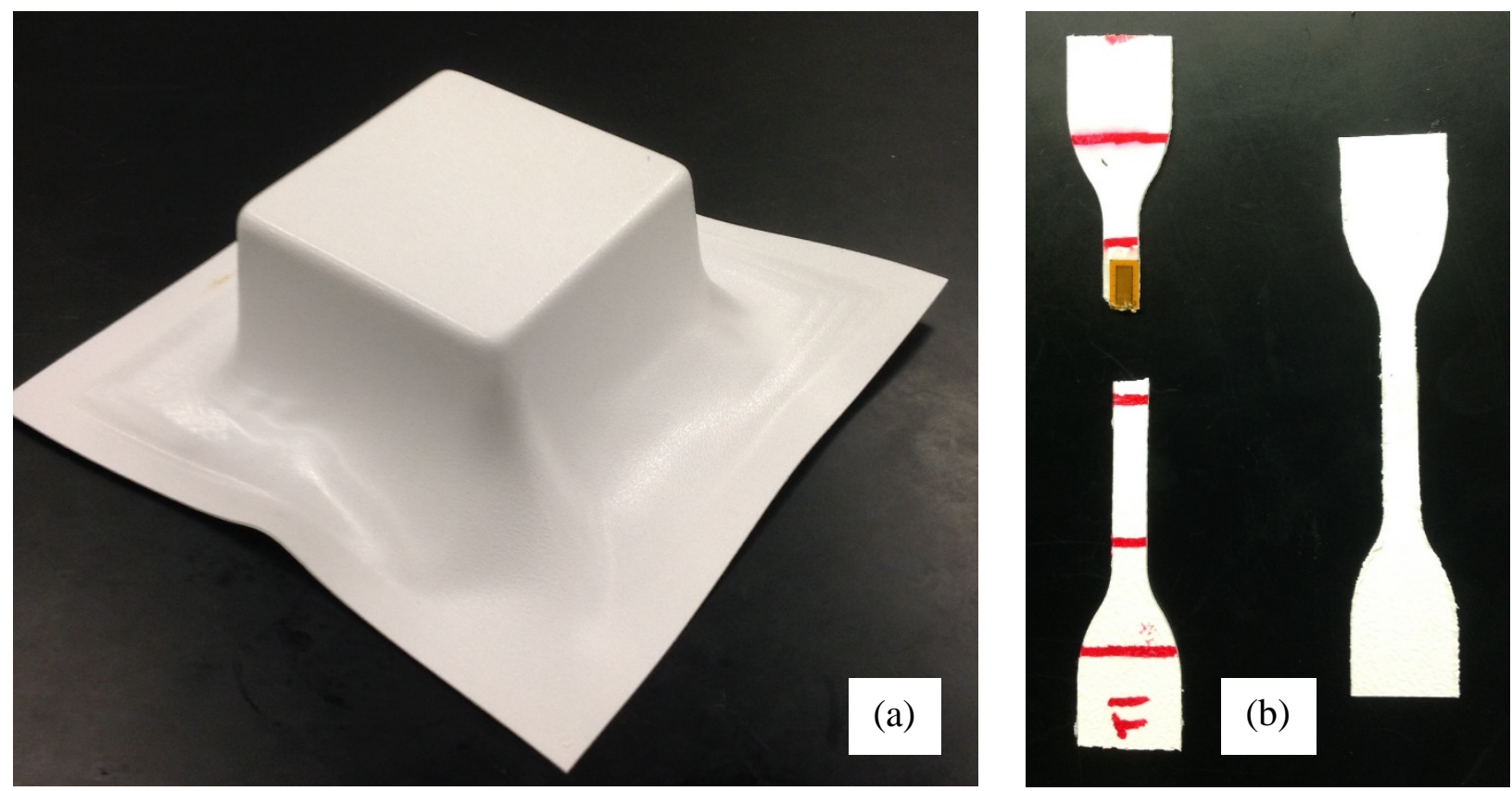

Figure 7: ABS material (a) after thermoforming into a trapezoidal shape, and (b) tensile test specimens cut from thermoformed material.

\section{Reflections}

We need to start by admitting that the project was a success. There was a lot more that we had envisioned doing at the beginning with materials (exotics, buckyball composites, nylon composites) and experimentation (torsion, fatigue, impact), but we came back down to earth a bit through the project. We were not the first group to learn that the scope of the project should be modest [5]. Although the 3D printer and thermoforming machine may not be suitable for 
common use around our department, the students did build and used both machines to produce experimentation specimens. They further went on to conduct individual research, and each student arrived at some meaningful results.

\subsection{Group Dynamics}

The students were friends from the start, and that probably helped them manage the stress of the project. Tough projects, time pressure, things not working... these are all seeds of frustration. The project certainly got the best of the students at times. We heard more than one negative comment about "so-and-so" in his absence. Fortunately the project did not ruin any friendships (that we are aware), but we wonder how a similar project would go with students who knew each other less well at the outset. Overall, there was definitely room for more professionalism, but the stick bent without breaking. Each student was, in the end, willing to put forth the needed work. One lagged behind for several weeks, but not to the point of throwing the project into turmoil.

\subsection{Formative Assessment}

It was beneficial to let the students have a strong say in outlining the objectives and deliverables for the project. That likely added to their commitment to the project when it took more time/effort than the students expected. They likely said to themselves "Well, we said that we would do this, so let's get it done.” We are sure graduation and jobs provided some motivation too! The freedom for the students to decide much of the project objectives came with two downsides: (1) overestimation of workload on their part, and (2) less time to conduct experiments because most of the extra work revolved around getting the fabrication machines up and running.

\subsection{If We Were to Do It All Over Again...}

It would be nice to see how far a group of students could get with the project if they were not designing and building the machines themselves. York College of PA has a few 3D printing machines and access to local companies with thermoforming machines. There is a balance between letting the students lead and pushing them toward a better path. If the group had the better part of two whole semesters to run experiments, they would learn a lot more about research, experimentation, and material properties. Our students already get a lot of hands-on design work, particularly in Capstone Design I and II, and this project probably had too much redundancy in that area. Design and fabrication skills are, however, essentials for mechanical engineers and extra experience in this area is not wasted. Admittedly, skipping the design/fabrication phase would be a big change from what we actually did, but giving the students less vote and pushing them towards experimentation on specimens fabricated by purchased or available machines may have produced a better overall result.

\subsection{Potential to Continue the Work}

We do not have immediate plans to continue the work. It was a successful project, but it needed the right group of students, and it would need a good group to continue. There are opportunities to improve the equipment and/or continue experimentation, but a good group of students interested in materials and experimentation is more important than task specifics. We are neither pursuing another round of the work nor opposed to that idea if the right opportunity arises. The 3D printer is still assembled and functional. We have not yet decided whether a permanent home for it in our building is warranted, or if we will need to disassemble it for parts and scrap. 


\section{Summary and Conclusions}

When four senior Mechanical Engineering students showed interests in advanced materials topics after taking the curriculum-standard Materials Science course, a few York College of PA professors designed a two-semester independent study plan. This opportunity exposed the students to undergraduate research and provided a mechanism for faculty at a teaching-focused college to pursue new research opportunities. The students designed and built a 3D printer and thermoforming machine. They used these machines to produce ASTM test specimens and study material properties in four sub-topics. Each student produced meaningful technical results. Two of the four students had planned to attend graduate school, but only one has as of yet (the other accepted an industry job).

On project conclusion, we note several aspects of this research-focused independent study that worked well or could be improved:

1. It was essential to extend this work across two semesters to complete all phases of the project: design, build, make samples, test, and analyze. One semester may have been sufficient for materials experiments only, but not with designing and building our own machines.

2. It was important to have a set of motivated students. Often the project required additional work, and the students' drive to see it through was essential. The project would not have been successful without strong student commitment.

3. Student motivation was likely increased by a large student voice in defining the projects. They were committed to completing objectives that they chose. There is a clear downside, however, to letting student preference drive the project tasks: they are prone to underestimate workload. Faculty must be careful to not let students set themselves up for failure.

4. Undergraduate students still lack some maturity needed to work together on a major project. Nerves and frustration almost spoiled positive feelings about the research. Fortunately, these frustrations did not ultimately get the best of the students or the project.

5. It was important to have well-defined goals, but some flexibility in project task deadlines was necessary because of unforeseen obstacles.

6. It may have been better to steer the students away from building their own fabrication equipment, as this required an incredible amount of time, and push them toward more time with experiments on samples made by existing/purchased machines. There is, however, a balance between directing students to the best research path and letting them take ownership over the project. 


\section{References}

1. G. D. Kuh, High-impact educational practices: what they are, who has access to them, and why they matter. Association of American Colleges and Universities, Washington, DC, 2008.

2. S. H. Russell, M.P. Hancock, and J. McCullough, "The pipeline: Benefits of undergraduate research experiences,” Science, vol. 316, pp. 548-549, Apr. 2007.

3. R. S. Hathaway, B. A. Nagda, and S. R. Gregerman, "The Relationship of undergraduate research participation to graduate and professional education pursuit: An empirical study,” Journal of College Student Development, vol. 43, no. 5, pp. 614-631, 2002.

4. D. Schaefer and J. Panchal, "Incorporating research into undergraduate design courses: a patent-centered approach,” International Journal of Mechanical Engineering Education, vol. 37, no. 2, pp. 98-110, 2009.

5. D. Friend and J. N. Beneat, "Development of aerospace engineering-focused undergraduate research at a small university: accomplishments and lessons learned," ASEE Annual Conference and Exposition, Atlanta, GA, June 23-26, 2013.

6. R. D. Engelken, "Participation of undergraduates in engineering research: evolving paradigms over three decades of change," ASEE Annual Conference and Exhibition, Louisville, KY, June 20-23, 2010.

7. E. Larson and A. Miguel, "Performing Engineering Research at Non-Ph.D. Granting Institutions," ASEE Annual Conference and Exhibition, Honolulu, HI, June 24-27, 2007.

8. P. Schuster and C. Birdsong, "Research in the Undergraduate Environment," ASEE Annual Conference and Exhibition, Chicago, IL, June 18-21, 2006.

9. R. D. Engelken, "Engineering research at predominately undergraduate institutions: Strategies and pitfalls for the new engineering educator," ASEE Annual Conference and Exhibition, Charlotte, NC, June 20-23, 1999.

10. E. M. Brey, M. F. Campanile, and N. G. Lederman, "Evaluation of a nine year summer undergraduate research program in biomedical engineering,” ASEE Annual Conference and Exhibition, Seattle WA, June 14-17, 2015.

11. J. Fairley, L. Conrad, and G. May, "The Importance of Graduate Mentors in Undergraduate Research Programs," ASEE Annual Conference and Exposition, Honolulu, HI, June 24-27, 2007.

12. S. Kaul, C. W. Ferguson, P. M. Yanik, and Y. Yan, "Importance of Undergraduate Research: Efficacy and Student Perceptions," ASEE Annual Conference and Exhibition, New Orleans, LA, June 26-29, 2016.

13. A. L. Zydney, J. S. Bennett, A. Shahid, and K. W. Bauer, "Impact of undergraduate research experience in engineering," Journal of Engineering Education, vol. 91, pp. 151157, 2002.

14. M. Boyd, and J. Wesemann, Broadening participation in undergraduate research: fostering excellence and enhancing the impact, Council on Undergraduate Research, Washington, DC, 2009. 
15. D. J. Lilja, "Suggestions for teaching the engineering research process," ASEE Annual Conference and Exhibition, Milwaukee, WI, June 15-18, 1997.

16. W. Stone, "Using undergraduate research as a recruitment tool for graduate study," ASEE Annual Conference and Exhibition, Vancouver, BC, June 26-29, 2011.

17. A. Minerick and B. Elmore, "Using Research as a Tool for Student Recruiting," ASEE Annual Conference and Exposition, Chicago, IL, June 18-21, 2006.

18. M. K. Eagan, S. Hurtado, M. J. Chang, G. A. Garcia, F. A. Herrera, and J. C. Garibay, "Making a difference in science education: The impact of undergraduate research programs," American Education Research Journal, vol. 50, pp. 683-713, 2013.

19. S. Brunhaver, S. K. Gillmartin, M. M. Grau, S. Sheppard, and H. L. Chen, "Not all the same: A look at early career engineers employed in different sub-occupations," ASEE Annual Conference and Exposition, Atlanta, GA, June 23-26, 2013.

20. MP. Beaufait, D. Chen, C. B. Dietrich, C. Dietrich, and G. M. Vanhoy, "Transition from undergraduate research program participants to researchers and open source community contributors,” ASEE Annual Conference and Exhibition, Vancouver, BC, June 26-29, 2011.

21. K. Luchini-Colbry, "Exploring the experience of undergraduate research: a case study using Facebook," ASEE Annual Conference and Exposition, Atlanta, GA, June 23-26, 2013.

22. A. Bellini and S. Guceri, "Mechanical characterization of fused deposition modeling," Rapid Prototyping Journal, vol. 9, no. 4, pp. 252-264, 2003. 